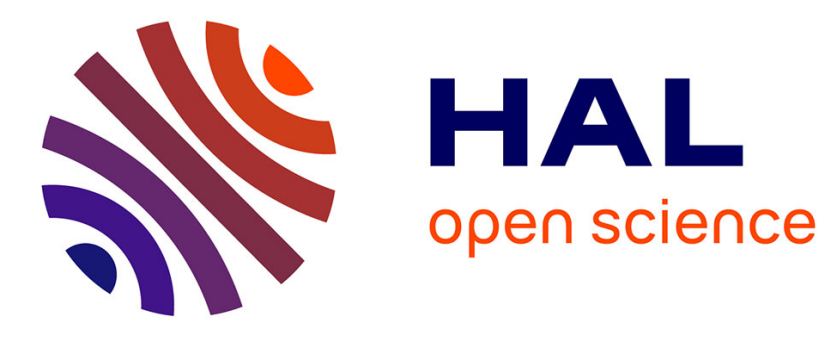

\title{
Insight into the Ferrier rearrangement by combining flash chemistry and superacids
}

Naresh Bhuma, Ludivine Lebedel, Hiroki Yamashita, Yutaka Shimizu, Zahra

Abada, Ana Ardá, Jérôme Désiré, Bastien Michelet, Agnès Martin-Mingot, Ali Abou-Hassan, et al.

\section{To cite this version:}

Naresh Bhuma, Ludivine Lebedel, Hiroki Yamashita, Yutaka Shimizu, Zahra Abada, et al.. Insight into the Ferrier rearrangement by combining flash chemistry and superacids. Angewandte Chemie International Edition, 2021, 60 (4), pp.2036-2041. 10.1002/anie.202010175 . hal-03007376

\section{HAL Id: hal-03007376 https://hal.science/hal-03007376}

Submitted on 1 Dec 2020

HAL is a multi-disciplinary open access archive for the deposit and dissemination of scientific research documents, whether they are published or not. The documents may come from teaching and research institutions in France or abroad, or from public or private research centers.
L'archive ouverte pluridisciplinaire HAL, est destinée au dépôt et à la diffusion de documents scientifiques de niveau recherche, publiés ou non, émanant des établissements d'enseignement et de recherche français ou étrangers, des laboratoires publics ou privés. 


\title{
Insight into the Ferrier rearrangement by combining flash chemistry and superacids
}

\author{
Naresh Bhuma, ${ }^{[a]}$ Ludivine Lebedel, ${ }^{[a]}$ Hiroki Yamashita, ${ }^{[b]}$ Yutaka Shimizu, ${ }^{[b]}$ Zahra Abada, ${ }^{[a],[c]}$ Ana \\ Ardá, ${ }^{[\mathrm{d}]}$ Jérôme Désiré, ${ }^{[a]}$ Bastien Michelet, ${ }^{[a]}$ Agnès Martin-Mingot, ${ }^{[a]}$ Ali Abou-Hassan, ${ }^{[c]}$ Masahiro \\ Takumi, ${ }^{[b]}$ Jérôme Marrot, ${ }^{[e]}$ Jesús Jiménez-Barbero, ${ }^{*[]]}$ Aiichiro Nagaki, ${ }^{*}[b]$ Yves Blériot ${ }^{*}[a]$ and \\ Sébastien Thibaudeau* ${ }^{\text {[a] }}$
}

In memory of Professor Jun-ichi Yoshida
[a] Dr. N. Bhuma, Dr. L. Lebedel, Dr. Z. Abada, Dr. J. Désiré, Dr. B. Michelet, Dr. A. Martin-Mingot, Prof. Y. Blériot, Prof. S. Thibaudeau IC2MP UMR CNRS 7285, Equipe "Synthèse Organique", Université de Poitiers, 4 rue Michel Brunet 86073 Poitiers cedex 9, France. E-mail: sebastien.thibaudeau@univ-poitiers.fr; yves.bleriot@univ-poitiers.fr
[b] Mr. H. Yamashita, Mr. Y. Shimizu, Mr. M. Takumi, Prof. A. Nagaki Department of Synthetic and Biological Chemistry, Graduate School of Engineering, Kyoto University, Japan. E-mail: anagaki@sbchem.kyoto-u.ac.jp
[c] Dr. Z. Abada, Prof. A. Abou-Hassan Sorbonne Université, CNRS UMR 8234, PHysico-chimie des Électrolytes et Nanosystèmes InterfaciauX (PHENIX), F-75005 Paris, France.
[d] Dr. A. Ardá, Prof. J. Jiménez-Barbero CIC bioGUNE, Parque technologico de Bizkaia, Edif. 801A-1º, Derio-Bizkaia 48160, and Ikerbasque, Basque Foundation for Science, Maria Lopez de Haro 3, 48013 Bilbao, Spain.
E-mail: jjbarbero@cicbiogune.es
[e] Dr. J. Marrot
Institut Lavoisier de Versailles, UMR CNRS 8180, 45 avenue des Etats-Unis, Versailles 78035 Cedex, France.

Supporting information for this article is given via a link at the end of the document

\begin{abstract}
The transformation of glycals into 2,3-unsaturated glycosyl derivatives, reported by Ferrier in 1962, is supposed to involve an $\alpha, \beta$ unsaturated glycosyl cation, an elusive ionic species that has still to be observed experimentally. Herein, while combination of $\mathrm{TfOH}$ and flow conditions failed to observe this ionic species, its extended lifetime in superacid solutions allowed its characterization by NMRbased structural analysis, supported by DFT calculations. This allyloxycarbenium ion was further exploited in the Ferrier rearrangement to afford unsaturated nitrogen-containing $C$-aryl glycosides and $C$-alkyl glycosides under superacid and flow conditions respectively.
\end{abstract}

The Ferrier I rearrangement (or Ferrier reaction) ${ }_{,}^{[1-2]}$ first reported in 1962 by Ferrier ${ }^{[3]}$ and earlier observed by Fisher, ${ }^{[4]}$ is considered as the prevalent route to hex-2-enopyranoses or pseudoglycals, species that hold a great synthetic potential in carbohydrate chemistry. ${ }^{[5,6]}$ Typically, this reaction is carried out with a glycal 1 having a good leaving group (e.g., acetate, carbonate, or trichloroacetimidate) at C-3 position, which after activation and allylic rearrangement, ${ }^{[7]}$ generates the corresponding pseudoglycal 2 (Figure $1 \mathrm{~A}$ ). It is now accepted that, in reactions involving alcohols as nucleophiles under acidic conditions, the resulting pseudoglycals are very labile and anomerize, favoring the $\alpha-O$-glycosides as a reflection of a thermodynamic control. On the opposite, the stereoselective formation of $C$-glycosides, unlikely to be a reversible process, is supposed to be under kinetic control. ${ }^{[8]}$ Undoubtedly, the conformation of glycal 1 plays an all-important role in the Ferrier rearrangement. The vinylogous anomeric effect, the anomeric effect extended through a $\mathrm{C}=\mathrm{C}$ double bond, must dictate a preferred pseudoaxial orientation of the leaving group at C-3 in the starting glycal. $^{[9]}$

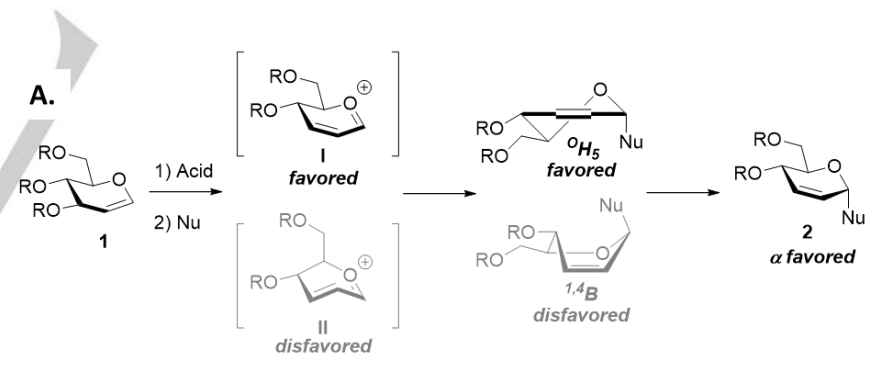

B.

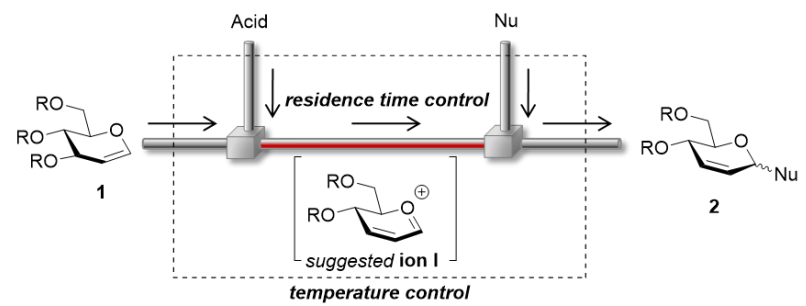

c.

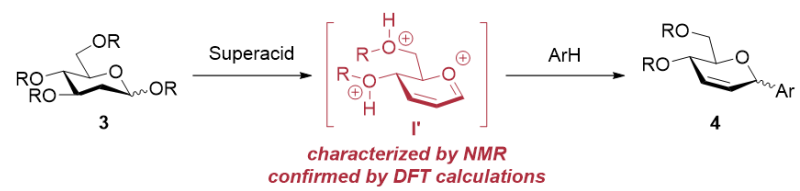

Figure 1. A. Ferrier rearrangement; B. Accumulation of allyloxycarbenium ion I under flash conditions and its reaction with $C$-nucleophiles in flow; $\mathbf{C}$. Superacidpromoted generation, low-temperature in situ NMR characterization, conformational analysis and use in $C$-arylation of the short-lived protonated allyloxycarbenium ion l'. 
The conformation of the postulated oxocarbenium ion intermediate (adopting the preferred conformation I over conformation II according to calculations) ${ }^{[10,11]}$ as well as the favored product conformation $\left({ }^{\circ} \mathrm{H}_{5}\right.$ over $\left.{ }^{1,4} \mathrm{~B}\right)$ must also contribute to the $\alpha$-selectivity (Figure 1A). ${ }^{[12]}$ The anchimeric assistance by the protecting group at $\mathrm{C}-4$ to ease the departure of the leaving group at $\mathrm{C}-3$ has also been postulated to rationalize the stereochemical outcome of the Ferrier rearrangement. ${ }^{[13]}$ In comparison with a classical glycosyl cation, the additional conjugation into the vinyl group enhances the stabilization of the allyloxycarbenium ion, suggesting its classification as a stabilized ion, ${ }^{[14]}$ thus theoretically favoring its direct observation by spectroscopic methods. Surprisingly, despite its crucial role in the Ferrier reaction, this species remains however hypothetical to the best of our knowledge. We report herein our efforts to characterize this elusive ion combining flow microreactors (Figure 1B), superacid chemistry, NMR analysis and DFT calculations and its use as a glycosyl donor to generate unprecedented nitrogen-containing $C$-aryl hex-2-enopyranosides (Figure 1C).

The cation-flow method, ${ }^{[15]}$ in which highly reactive cations are rapidly generated in the absence of nucleophiles using the integrated flow microreactor, is quite effective for the generation of alkoxycarbenium ions ${ }^{[16]}$ and for performing glycosylation reactions involving glycosyl cation intermediates based on an indirect method. ${ }^{[17]}$ To evaluate the ability of this method to generate and exploit the related Ferrier cation, the commercially available tri-O-acetyl-D-glucal 1a was chosen as a model substrate. Using an integrated flow microreactor system consisting of two micromixers (M1 and $\mathrm{M} 2$ ) and two microtube reactors ( $\mathrm{R} 1$ and $\mathrm{R} 2$ ), the treatment of a dichloromethane solution of 1a with triflic acid (TfOH) followed by allyltrimethylsilane to generate the known $C$-glycoside $2 \mathrm{a}^{[18]}$ was examined (Figure 2).
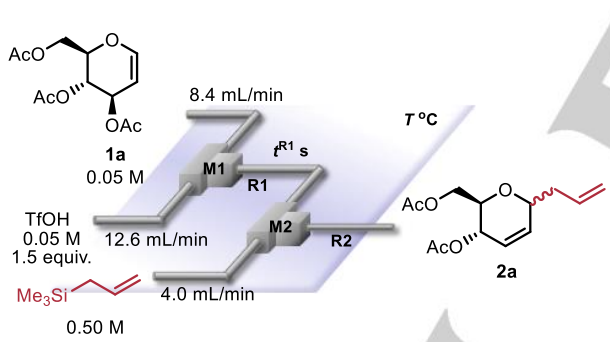

Figure 2 Integrated flow microreactor system for the production of $C$-allyl pseudo-glycal 2a from glycal 1a. T-shaped micromixers: M1 and M2, microtube reactors: R1 and $\mathrm{R} 2$.

The reactions were carried out at a range of residence times in R1 $\left(t^{\mathrm{R} 1}\right)$ and a variety of temperatures $(T)$. The results are summarized in Figure 3 , in which the yield of $2 \mathbf{a}$ is plotted against $T$ and $t^{\mathrm{R} 1}$ as a contour map with a scattered overlay. The yield of 2a strongly depends on the residence time and the temperature. At high temperatures with longer residence times, the yield was low presumably because of the decomposition of the generated cation. At low temperatures, the yield was also low for a short $t^{\mathrm{R} 1}$ probably because of the incomplete generation of the cation. However, $2 \mathrm{a}$ was obtained in $83 \%$ yield $(\alpha / \beta=91: 9)$ by choosing $T=-30{ }^{\circ} \mathrm{C}$ and $t^{\mathrm{R} 1}=0.6$ seconds as the optimized conditions. Whatever the conditions used, it is worth noting that the $\alpha$ anomer is formed as the major isomer, in accordance with the kinetic trapping of cation of type I from the lower face of the sugar ring.

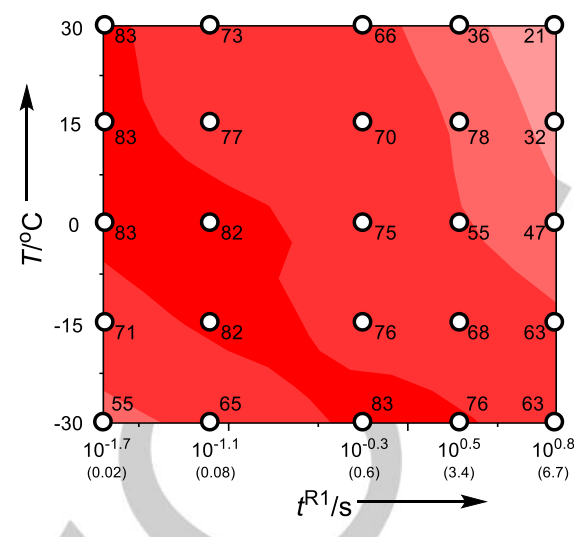

Figure 3. Effects of temperature $(T)$ and residence time in $\mathrm{R} 1\left(t^{\mathrm{R} 1}\right)$ on the yield (\%) of $2 \mathbf{a}$ from the reaction of the glucal 1a with triflic acid $(\mathrm{TfOH})$ and subsequent reaction with allyltrimethylsilane in the flow microreactor system.

This result was further exemplified by applying the method to various nucleophiles and D-glucals to produce a set of pseudoglycals 2 (Table 1 ).

Table 1 : Flow microreactor synthesis of functionalized pseudo glycals 2 from D-glucals 1.

Entry 1 (glycal) nucleophile

Under the optimized reaction conditions, the known ${ }^{[19]}$ pseudoglycal 2a' could be generated in $91 \%$ yield from 1a and 1phenyl-1-trimethylsiloxyethylene (Table 1 , entry 2 ). The reactivity of trimethoxy D-glucal 1b was also examined using the flow microreactor system. As summarized in Table 1, trimethoxy Dglucal 1b was also effective as a glycosyl donor, allowing the coupling of various nucleophiles. Allyltrimethylsilane, 1-phenyl-1trimethylsiloxyethylene and $n$-BuLi gave the corresponding $C$ alkyl glycosides $\mathbf{2 b},{ }^{[20]} \mathbf{2} \mathbf{b}$ ' and $\mathbf{2} \mathbf{b}$ " in good to excellent yields. In all cases, an $\alpha$ stereochemical outcome was observed that can be tentatively explained by the pseudo-axial attack on the $\alpha$-face of the ${ }^{4} \mathrm{H}_{3}$ conformer of the transient 2-deoxyglucopyranosyl 
oxycarbenium ion as previously observed ${ }^{22 a}$ while a long-range participation by the ester or ether at C-4 can not be excluded. ${ }^{13 \mathrm{c}, 13 \mathrm{~d}}$ We finally evaluated the ability of the flow microreactor system to generate and accumulate ion I to allow its observation by NMR. Unfortunately, treatment of glucal $\mathbf{1}$ with $\mathrm{TfOH}$ failed to afford clean NMR spectra under these conditions (see SI).

Strongly inspired by the work of Olah and Prakash, who unlocked large areas of carbocation chemistry exploiting non nucleophilic superacid conditions, ${ }^{[21]}$ our team has used $\mathrm{HF} / \mathrm{SbF}_{5}$ superacid as both reagent and solvent to generate and characterize several glycosyl cations in the condensed phase. ${ }^{[22]}$ Following this strategy, we challenged the generation of ion $\mathbf{I}$ in superacid solutions and its observation by low-temperature NMR spectroscopy. The tri-O-acetyl-D-glucal 1a was first submitted to $\mathrm{HF} / \mathrm{SbF}_{5}$ and furnished a mixture of two polycationic species which were analyzed by NMR spectroscopy (Figure 4A).

A.

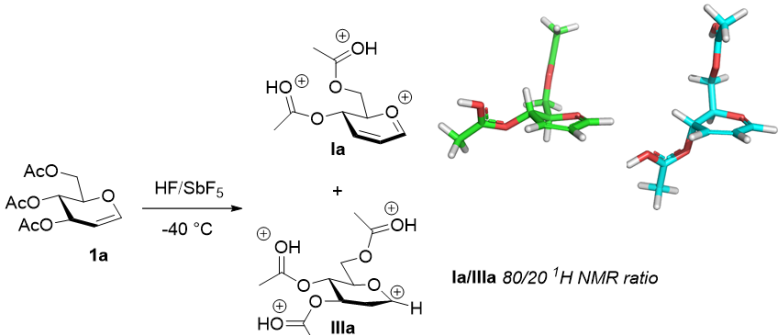

B.

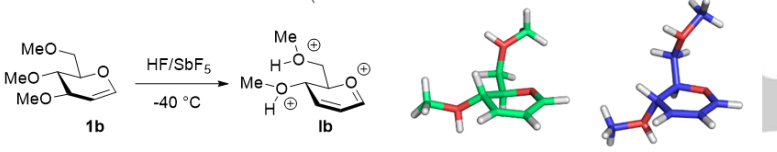

C.

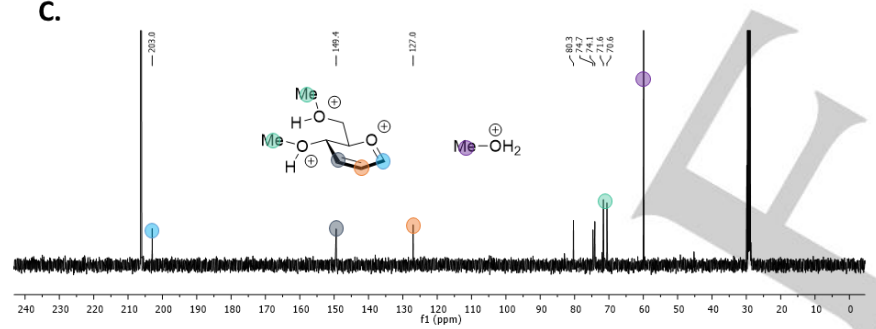

Figure 4. A. Generation of conjugated allyloxycarbenium ion la (conformations in solution confirmed by DFT analysis) and glycosyl cation Illa from tri-O-acetylD-glucal 1a in $\mathrm{HF} / \mathrm{SbF}_{5}$ at $-40{ }^{\circ} \mathrm{C}$ (conformations in solution confirmed by DFT analysis); B. Generation of allyloxycarbenium ion Ib from tri-O-methyl-D-glucal 1b in $\mathrm{HF} / \mathrm{SbF}_{5}$ at $-40{ }^{\circ} \mathrm{C}$ (conformations in solution confirmed by DFT analysis); C. Low-temperature ${ }^{13} \mathrm{C}$ NMR spectrum of cation $\mathbf{l b}$ in $\mathrm{HF} / \mathrm{SbF}_{5}$ solution.

Detailed NMR analysis confirmed the presence the resonancestabilized glycosyl cation la (anomeric proton at $\delta=8.30 \mathrm{ppm}$ and anomeric carbon at $\delta=202.4 \mathrm{ppm}$ ). The shielding of the anomeric carbon and proton compared to the 2-deoxyglucosyl cation ${ }^{[22 a]}$ can be rationalized by the increased stabilization of the carbocation by conjugation. The presence of a $\mathrm{C}=\mathrm{C}$ bond in this species was evidenced by two signals at 6.29 and $6.75 \mathrm{ppm}$ in the ${ }^{1} \mathrm{H}$ NMR spectrum and two peaks at 152.3 and $125.4 \mathrm{ppm}$ in the ${ }^{13} \mathrm{C}$ NMR spectrum. In addition, the protonated acetates are characterized by two singlets at $12 \mathrm{ppm}<\delta<14 \mathrm{ppm}$ in the ${ }^{1} \mathrm{H}$ NMR spectrum. Beside ion la, the presence of the known 2deoxyglucosyl cation IIla was also detected in the reaction crude according to characteristic NMR signals (see SI). ${ }^{[22 a]}$ In the presence of Brønsted acid catalysts, glycals undergo nucleophilic displacement (Ferrier-type reaction) but can also experience functionalization at $\mathrm{C} 1$ to yield 2-deoxy derivatives, via postulated oxycarbenium ions. ${ }^{[23]}$ Here, the observation of ion Illa further reinforces this hypothesis. Performing the reaction at higher temperatures increased the la/ Illa ratio suggesting that ion Illa is a precursor of ion la in this process (ref $\mathrm{SI}$ ). To drive the reaction to the exclusive formation of conjugated glycosyl cation, we switched to trimethoxy D-glucal $\mathbf{1 b}$ and submitted it to the same superacid conditions (Figure 4B). Unlike in a classical organic environment, ${ }^{[24]}$ the methoxy substituent has proved to be a superior leaving group under superacid activation compared to the acetyl group. Satisfyingly, one major polycationic species was observed by NMR whose signals were in good agreement with the conjugated glycosyl cation lb displaying an anomeric proton at $\delta=8.45 \mathrm{ppm}$ and an anomeric carbon at $\delta=203.0 \mathrm{ppm}$ (Figure $4 \mathrm{C})$. The protonation of the methoxy groups was evidenced by a signal at $9.81 \mathrm{ppm}\left({ }^{1} \mathrm{H}-\mathrm{NMR}\right)$ and two signals at 70.6 and 71.6 ppm $\left({ }^{13} \mathrm{C}-\mathrm{NMR}\right)$. The departure of the $\mathrm{CH}_{3} \mathrm{O}$ group at $\mathrm{C}-3$ was confirmed by the observation of the methyloxonium ion at 60.0 $\mathrm{ppm},{ }^{[25]}$ and the formation of a $\mathrm{C}=\mathrm{C}$ bond evidenced by two doublets of doublets at $6.86 \mathrm{ppm}(J=9.8 \mathrm{~Hz}$ and $J=4.2 \mathrm{~Hz})$ and $6.48 \mathrm{ppm}(J=9.9 \mathrm{~Hz}$ and $J=1.9 \mathrm{~Hz})$ in the ${ }^{1} \mathrm{H}-\mathrm{NMR}$ spectrum and two signals at 149.4 and $127.0 \mathrm{ppm}\left({ }^{13} \mathrm{C}-\mathrm{NMR}\right)$. The quality of the recorded NMR spectra allowed complete analysis of the homonuclear ${ }^{1} \mathrm{H}$-NMR coupling constants for both species la and Ib, enabling access to their conformational preferences in solution, by comparing the experimental ${ }^{3} \mathrm{~J}(\mathrm{H}, \mathrm{H})$ coupling constants with those predicted for DFT calculated structural models (see SI). The planarity of the sugar ring at the O5-C1-C2-C3 moiety was thus confirmed, while the situation around the C3-C4-C5-O5 bonds was demonstrated to be more flexible. Indeed, for both species the experimental values ${ }^{3} \mathrm{~J}(\mathrm{H} 3, \mathrm{H} 4)=4.3-4.5 \mathrm{~Hz}$, and ${ }^{3} \mathrm{~J}(\mathrm{H} 4, \mathrm{H} 5)=$ $5.0-5.2 \mathrm{~Hz}$ (see SI) necessarily entailed the existence of a conformational equilibrium. DFT calculations (see SI) identifed two enery minima very close in energy $(0.8$ and $3.2 \mathrm{~kJ} / \mathrm{mol}$ for la and $\mathrm{Ib}$ respectively) (Figures $4 \mathrm{~A}$ and $4 \mathrm{~B}$ and $\mathrm{SI}$ ) for which the combination of their NMR parameters fulfill the experimentally observed ones.

Because of the potential bioactivity as well as the synthetic challenges associated with aryl $C$-glycosides, this class of carbohydrates has attracted considerable interest and extensive research aiming at developing new chemical strategies and tactics toward aryl $C$-glycosides. ${ }^{[26]}$ The carbon-Ferrier rearrangement is considered as one of the most prevalent and straightforward approaches to access $C$-glycosides, ${ }^{[2 c]}$ that are distinct motifs embedded in various biologically active natural products. ${ }^{[6 \mathrm{~d}, 26]}$ Acid-promoted reaction of glycals with good nucleophiles such as alkynyl and allylsilanes, silyl enol ethers or organometallics is especially efficient to generate $C$-glycosides. ${ }^{[2 \mathrm{c}]}$ However, standard procedures to generate $C$-aryl glycosides through acid-promoted Ferrier rearrangement with aromatics is scarcely reported ${ }^{[27]}$ and subject to the undesired formation of rearranged products when dealing with functionalized aromatics due to heteroatom nucleophilicity. ${ }^{[28]}$ Capitalizing on the ability to generate Ferrier cation of type $\mathrm{I}$ in $\mathrm{HF} / \mathrm{SbF}_{5}$ solution, on previous Friedel-Crafts type reactions achieved in superacid ${ }^{[29]}$ and on the protection of the nitrogen atom(s) by protonation in superacid, the generation of nitrogen-containing aryl $C$-glycosides from Ferrier cation precursor in superacid was explored. In batch conditions, the tri-O-acetyl-D-glucal 1 a was submitted to $\mathrm{HF} / \mathrm{SbF}_{5}$ conditions 
in the presence of $p$-methylacetanilide as a model arene, affording the desired $C$-aryl hex-2-enopyranoside 4 a albeit in low yield with the formation of several side products with undetermined structure. A similar trend was observed with other arenes, definitely discarding the use of glycals as glycosyl donors to generate $C$-aryl glycosides in $\mathrm{HF} / \mathrm{SbF}_{5}$. As mentioned above, the glycosyl cation IIla can lead to a conjugated ion la upon acid activation and subsequent elimination of the C-3 acetate group. This suggests that the treatment of a 2-deoxy glycosyl donor in the presence of an arene under superacid conditions at a temperature above $-40{ }^{\circ} \mathrm{C}$ might generate a $C$-aryl glycoside intermediate that would undergo further elimination to afford the desired $\quad C$-aryl-hex-2-enopyranoside. This hypothesis was confirmed by the direct observation of la (and Illa) when submitting 2-deoxy glucosyl donor $\mathbf{3}$ to superacid solution the la/llla ratio increasing over time and temperature increase (see $\mathrm{SI}$ ). A preliminary trial at $-40{ }^{\circ} \mathrm{C}$ with donor 3 and $p$ methylacetanilide yielded $4 \mathrm{a}$ in $16 \%$ yield (Table 2 , entry 1 ). Performing the reaction at lower acidity failed to furnish the desired compound even on a prolonged reaction time (Table 2, entry 2). ${ }^{[30]}$ However, carrying out the reaction at slightly higher temperature and at a lower concentration proved beneficial (Table 2 , entries 3-5). Conducting the reaction with a substrate concentration in solution of $0.038 \mathrm{~mol} . \mathrm{L}^{-1}$ was found to be the best compromise for a good conversion and a selective transformation, decreasing the amount of undetermined side products (Table 2, entries 6-7). The amount of nucleophilic partner could even be reduced to 1.5 equiv. by performing the reaction at $-20{ }^{\circ} \mathrm{C}$ for $10 \mathrm{~min}$, affording the desired product $4 \mathrm{a}$ in $72 \%$ yield (Table 2 , entry 8 ).

Table 2. Optimization of C-arylation conditions applied to 2-deoxyglucosyl donor $\mathbf{3}$ to access pseudoglycal $\mathbf{4 a}$.

\begin{tabular}{|c|c|c|c|c|c|}
\hline Entry & $\begin{array}{c}{[3]^{[a]}} \\
\left(\mathrm{mol} \cdot \mathrm{L}^{-1}\right)\end{array}$ & $\begin{array}{c}\left.\left[\mathrm{SbF}_{5}\right]^{[\mathrm{b}]}\right] \\
(\mathrm{mol} \%)\end{array}$ & $n$ & Conditions & Yield $(\%)^{[c]}$ \\
\hline 1 & 0.15 & 8 & 3 & $-40^{\circ} \mathrm{C}, 10 \mathrm{~min}$ & 16 \\
\hline 2 & 0.15 & 4 & 3 & $-40^{\circ} \mathrm{C}, 4 \mathrm{~h}$ & -[d] \\
\hline 3 & 0.075 & 8 & 3 & $-20^{\circ} \mathrm{C}, 10 \mathrm{~min}$ & 19 \\
\hline 4 & 0.019 & 8 & 3 & $-20^{\circ} \mathrm{C}, 10 \mathrm{~min}$ & 38 \\
\hline 5 & 0.019 & 8 & 3 & $-20^{\circ} \mathrm{C}, 2 \mathrm{~min}$ & 46 \\
\hline 6 & 0.038 & 8 & 3 & $-20^{\circ} \mathrm{C}, 4 \mathrm{~min}$ & 71 \\
\hline 7 & 0.038 & 8 & 2 & $-20^{\circ} \mathrm{C}, 5 \mathrm{~min}$ & 66 \\
\hline 8 & 0.038 & 8 & 1.5 & $-20^{\circ} \mathrm{C}, 10 \mathrm{~min}$ & 72 \\
\hline
\end{tabular}

[a] Substrate concentration in $\mathrm{HF} / \mathrm{SbF} 5$ solution. [b] Concentration of $\mathrm{SbF}_{5}$ relative to $\mathrm{HF}$ in $\mathrm{HF} / \mathrm{SbF}_{5}$ solution. [c] Isolated yield. [d] No reaction.

Interestingly, this Friedel-Crafts reaction is regioselective, as the carbohydrate unit is selectively inserted in ortho position to the methyl group of the acetanilide. This result can be correlated to the behaviour of nitrogen containing species in superacid solutions as in $\mathrm{HF} / \mathrm{SbF}_{5}$. Neutral acetamide function must be in equilibrium with its protonated form and the methyl group therefore orientates the electrophilic addition. ${ }^{[31]}$ The reaction is also stereoselective, the $\alpha$-isomer being formed predominantly through this process, whatever the conditions used $(\alpha / \beta$ ratio $=$ 85:15; entries 1 and 3-8). As demonstrated by low-temperature in situ NMR, 4a results from the concomitant nucleophilic trapping of la and IIla (followed by elimination) in solution (see SI).

To define the scope of this reaction, we screened a series of substituted arenes and heteroarenes (Figure 5). As previously observed for the formation of product $\mathbf{4 a}$, the reaction proceeded regioselectively and efficiently in the presence of methylated acetanilides (products $\mathbf{4 b}$ and $\mathbf{4 c}$ ). The structure of $\mathbf{4 b}$ was also confirmed by X-ray analysis of the collected crystals obtained after reaction of substrate 3 (see SI). ${ }^{[32]}$ Gratifyingly, halogenated aromatics could also be coupled to pseudo glycals, as shown by the formation of $\alpha$-product $\mathbf{4 d}$. Here again, the fluorine atom orientates the regioselectivity. More importantly, the Ferrier cation I was found to react with aniline with excellent stereoselectivity, albeit in a moderate yield (product $4 \mathbf{4 e}$ ). Considering that anilines must react in their protonated forms in superacid solutions, and thus acting as very poor ammonium-substituted nucleophiles, this result emphasizes the superelectrophilic character of the protonated Ferrier cation in superacid. ${ }^{[33]}$ The reaction was also operative with a protected phenol, expanding the method to oxygenated aromatics (product $\mathbf{4 f}$ ).

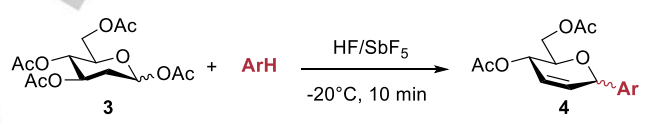
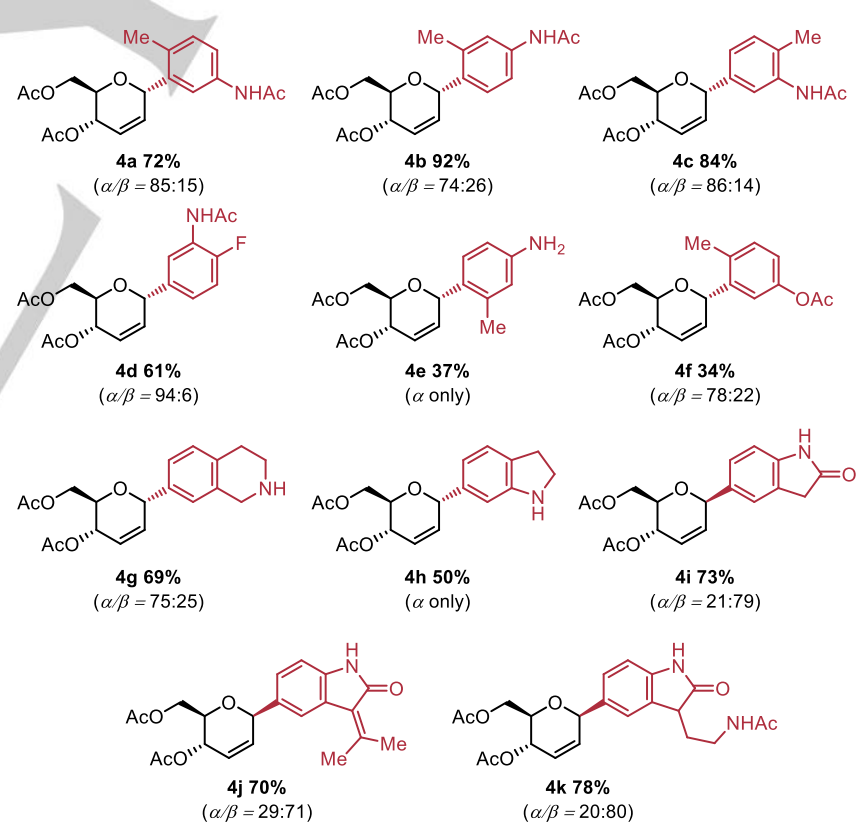

Figure 5. Scope of the C-arylation of peracetylated 2-deoxyglucopyranose mediated by HF/SbF 5 . Conditions from Table 2, entry 8.

The direct modification of nitrogen-containing natural products at a late stage of a synthetic plan is now considered as a tool of choice in drug discovery programs. ${ }^{[34]}$ To test the potential of our methodology in this context, the reactivity of the Ferrier cation la with several nitrogen containing aromatics was explored. To our delight, tetrahydroisoquinoline, indoline, oxindole as well as functionalized oxindoles could be stereoselectively and efficiently $C$-glycosylated in a regioselective manner (products $\mathbf{4 g - k}$ ). Noteworthy, the $\beta$-isomer is predominantly formed when glycosyl 
cation is trapped by oxindoles, a stereochemical outcome that is difficult to rationalize.

In conclusion, this study enabled to convert the cyclic allyloxycarbenium ion $\mathbf{I}$, the key intermediate in the Ferrier rearrangement, from an elusive species to a well-defined molecule. This cation was suggested to accumulate in the presence of triflic acid under flow conditions, and was further trapped by anionic C-nucleophiles. Exploiting non-nucleophilic $\mathrm{HF} / \mathrm{SbF}_{5}$ superacid solution, this cation was fully characterized by combining low-temperature NMR spectroscopy and DFT calculation. Its synthetic application in Ferrier rearrangements starting from 2-deoxyglucosyl donor produced a series of unprecedented nitrogen-containing $C$-aryl pseudoglycals.

\section{Acknowledgements}

LL, NB and ZA thank the Agence Nationale de la Recherche (ANR SweetCat) for $\mathrm{PhD}$ and post-doctoral grants. ST and YB acknowledge the European Union (ERDF), Région Nouvelle Aquitaine and the University of Poitiers for financial support. YB thanks the PRC CNRS JSPS program number 1706 for funding. JJB acknowledges the European Research Council for generous support (ERC-2017-AdG to JJB - Project number 788143RECGLYCANMR). AA and JJB thank Agencia Estatal de Investigación (Spain) for grants CTQ2015-64597-C2-1-P and Severo Ochoa Excellence Accreditation SEV-2016-0644. AN was partially supported by the Grant-in-Aid for Scientific Research on Innovative Areas 2707 Middle molecular strategy from MEXT (no. 15H05849), Scientific Research (B) (no. 26288049), Scientific Research (S) (no. 26220804), Scientific Research (S) (no. 25220913), Scientific Research (C) (no. 17865428), AMED (no. 18ak0101090h), the Japan Science and Technology Agency's (JST) A-step program (no. 18067420), CREST, and the Ogasawara Foundation for the Promotion of Science \& Engineering.

Keywords: glycosylation - oxycarbenium - Ferrier superelectrophile $\cdot C$-glycoside

[1] R. J. Ferrier, O. A. Zubkov, Org. React. 2003, 62, 569-736.

[2] For reviews, see: a) A. M. Gomez, S. Miranda, J. C. Lopez Carbohydr. Chem. 2017, 42, 210-247. b) A. M. Gomez, F. Lobo, C. Uriel, J. C. Lopez Eur. J. Org. Chem. 2013, 7221-7262. c) A. A. Ansari, R. Lahiri, Y. D. Vankar Arkivoc 2013, 2, 316-362.

[3] R. J. Ferrier, W. G. Overend, A. E. Ryan, J. Chem. Soc. 1962, 3667-3670.

[4] E. Fischer, Ber. Dtsch. Chem. Ges. 1914, 47, 196-210.

[5] A. M. Gomez, F. Lobo, S. Miranda, J. C. Lopez, Molecules 2015, 20, 8357 8394.

[6] For recent reviews on glycal and Ferrier reaction exploitation, see: a) C. S. Bennett, M. C. Galan, Chem. Rev. 2018, 118, 7931-7985. b) H. H. Kinfe, Org. Biomol. Chem. 2019, 17, 4153-4182. c) H. Liao, J. Ma, H. Yao, X-W. Liu, Org Biomol. Chem. 2018, 16, 1791-1806. d) E. Bokor, S. Kun, D. Goyard, M. Toth, J-P. Praly, S. Vidal, L. Somsak, Chem. Rev. 2017, 117, 1687-1764.

[7] For recent examples of glycal activation with trifluoromethanesulfonic acid and trifluoromethanesulfonate-based Lewis acids, see: a) P. Chen, S. Wang Tetrahedron 2013, 69, 583-588. b) G. Narasimha, B. Srinivas, P. R. Krishna, S. Kashyap Synlett 2014, 25, 523-526. c) P. Chen, S. Li Tetrahedron Lett. 2014, 55 , 513-5816. d) P. Chen, S. Wang, Tetrahedron 2012, 68, 5356-5262. e) B. G. Williams, S. B. Simelane, H. H. Kinfe Org. Biomol. Chem. 2012, 10, 5636-5642.

[8] For a selected example, see: S. J. Danishefsky, K. F. Kerwin, J. Org. Chem. 1982 47, 3803-3805.

[9] a) R. J. Ferrier, G. H. Sankey, J. Chem. Soc. C 1966, 2345-2349. b) A. R. Katritzky, P. J. Steel, S. N. Danisenko, Tetrahedron 2001, 57, 3309-3314. c) D. P. Curran, Y.-G. Suh, J. Am. Chem. Soc. 1984, 106, 5002-5004.

[10] Allyl oxocarbenium ion intermediate I generated from tri-O-acetyl-D-glucal has been recently estimated to be favored by $4.68 \mathrm{kcal} / \mathrm{mol}$ over II, see: N. Huang, H. Liao, H. Yao, T. Xie, S. Zhang, K. Zou, X. -W. Liu Org. Lett. 2018, 20, 16 19.
[11] Calculations performed on allyl oxocarbenium ion interemediates generated from di-O-acetyl-L-arabinal also indicated a predominant axial orientation of the 4OAc group, see: S. Hosokawa, B. Kirschbaum, M. Isobe Tetrahedron Lett. 1998, 39, 1917-1920.

[12] K. Le Mai Hoang, W. -L. Leng, Y. -J. Tan, X. -W. Liu Stereoselective Cglycosylation from glycal scaffolds, in Selective Glycosylations: Synthetic methods and catalysts; Wiley-VCH, 2017, pp 135-153.

[13] a) R. J. Ferrier, N. J. Prasad, J. Chem. Soc. 1969, 570-575. b) D. P. Curran, Y.G. Suh, Carbohydr. Res. 1987, 171, 161-191. For recent work on long-range participation by protecting groups see c) Hansen, T.; Elferink, H.; van Hengst, J. M. A.; Houthuijs, K. J.; Remmerswaal, W. A.; Kromm, A.; Berden, G.; van de Vorm, S.; Rijs, A. M.; Overkleeft, H. S.; Filippov, D. V.; Rutjes, F. P. J. T.; van der Marel, G. A.; Martens, J.; Oomens, J.; Codée, J. D. C.; Boltje, T. J. Nature Communications 2020, 11 (1). d) Marianski, M.; Mucha, E.; Greis, K.; Moon, S.; Pardo, A.; Kirschbaum, C.; Thomas, D. A.; Meijer, G.; Helden, G.; Gilmore, K.; Seeberger, P. H.; Pagel, K. Angewandte Chemie International Edition 2020 , 59, 6166-6171.

[14] F. Marchetti, G. Pampaloni, S. Zacchini, Dalton. Trans. 2009, 8096-8106.

[15] S. Suga, M. Okajima, K. Fujiwara, J. -I. Yoshida, J. Am. Chem. Soc. 2001, 123 , 7941-7942.

[16] S. Suga, K. Matsumoto, K; Ueoka, J. -I. Yoshida, J. Am. Chem. Soc. 2006, 128 , 7710-7711.

[17] K. Saito, K. Ueoka, K. Matsumoto, S. Suga, T. Nokami, J. -I. Yoshida, Angew. Chem. Int. Ed. 2011, 50, 5153-5156.

[18] P. Chen, J. Su, Tetrahedron 2016, 72, 84-94

[19] H. Y. Tong, S. Xiang, W. L. Leng, X. -W. Liu, RSC Adv. 2014, 4, 34816-34822

[20] P. Tiwari, G. Agnihotri, A. K. Misra, Carbohydr. Res. 2005, 340, 749-752.

[21] G. A. Olah, G. K. S. Prakash, A. Molnar, J. Sommer, Superacids, 2nd edn, Wiley Intersciences, New York, 2009

[22] a) A. Martin, A. Arda, J. Désiré, A. Martin-Mingot, N. Probst, P. Sinaÿ, J. Jiménez-Barbero, S. Thibaudeau, Y. Blériot, Nat. Chem. 2016, 8, 186-191. b) L. Lebedel, A. Arda, A. Martin, J. Désiré, A. Mingot, M. Aufiero, N. Aiguabella, R. Gilmour, J. Jimenez-Barbero, Y. Blériot, S. Thibaudeau, Angew. Chem. Int Ed. 2019, 58, 13758-13762; Angew. Chem. 2018, 131, 13896-13900. c) T. Hansen, L. Lebedel, W. A. Remmerswaal, S. van der Vorm, D. P. A. Wander, M Somers, H. S. Overkleeft, D. V. Filippov, J. Désiré, A. Mingot, Y. Blériot, G. A van der Marel, S. Thibaudeau, J. Codee, ACS Central Sci. 2019, 5, 781-788.

[23] a) H.-C. Lin, W.-P. Du, C.-C. Chang, C.-C. Lin, Tetrahedron Lett. 2005, 46 , 5071-5076. b) V. Bollit, C. Mioskowski, S. G. Lee, J. R. Falck, J. Org. Chem 1990, 55, 5812-5813. c) A. Fernandes, M. Dell'Olmo, A. Tatibouët, A. Imberty, C. Philouze, P. Rollin, Tetrahedron Lett. 2008, 49, 3484-3488.

[24] E. I. Balmond, D. M. Coe, M. C. Galan, E. M. McGarrigle Angew. Chem., Int. Ed. 2012, 51, 9152-9155.

[25] G. A. Olah, R. H. Schlosberg, J. Am. Chem. Soc. 1968, 90, 6464-6467.

[26] K. Kitamura, Y. Ando, T. Matsumoto, K. Suzuki, Chem. Rev. 2018, 118, 1495 1598.

[27] a) Y. Ichikawa, M. Isobe, M. Konobe, T. Goto, Carbohdyr. Res. 1987, 171, 193 199. b) N. R. Swamy, M. Srinivasulu, T. S. Reddy, T. V. Goud, Y Venkateswarlu, J. Carbohydr. Chem. 2004, 23, 435-441.

[28] For undesired intramolecular cyclization after reaction of glucals with anilines and phenols, see: a) J. S. Yadav, B. V. S. Reddy, K. V. Rao, K. S. Raj, A. R. Prasad, S. K. Kumar, A. C. Kunwar, P. Jayaprakash, B. Jagannath, Angew. Chem Int. Ed. 2003, 42, 5198-5201. b) S. B. Simelane, H. H. Kinfe, A. Muller, B. B G. Williams Org. Lett. 2014, 16, 4543-4545. c) C. Du, F. Li, X. Zhang, W. Hu, Q. Yao, A. Zhang J. Org. Chem. 2011, 76, 8833-8839.

[29] a) R. Beaud, B. Michelet, Y. Reviriot, A. Martin-Mingot, J. Rodriguez, D. Bonne, S. Thibaudeau Angew. Chem. Int. Ed. 2020, 59, 1279-1285; Angew. Chem. 2020 132, 1295-1301. b) U. Castelli, J-F. Lohier, I. Drukenmüller, A. Mingot, C. Bachman, C. Alayrac, J. Marrot, K. Stierstorfer, A. Kornath, A-C. Gaumont, S. Thibaudeau Angew. Chem. Int. Ed. 2019, 58, 1355-1360; Angew. Chem. 2019, 131, 1369-1374. c) L. J. C. Bonazaba Milandou, H. Carreyre, S. Alazet, G. Greco, A. Martin-Mingot, C. Nkounkou Loumpangou, J-M. Oumaba, F. Bouazza, T. Billard, S. Thibaudeau Angew. Chem. Int. Ed. 2017, 56, 169-172 Angew. Chem. 2017, 129, 175-178. d) N. Probst, A. Martin, J. Désiré, A. Mingot, J. Marrot, Y. Blériot, S. Thibaudeau Org. Lett. 2017, 19, 1040-1043.

[30] For studies on $\mathrm{HF} \mathrm{SbF}_{5}$ acidity evaluation, see: J.-C. Culmann, M. Fauconet, R. Jost, J. Sommer, New J. Chem. 1999, 23, 863-867 and references cited therein.

[31] Similar trends of reactivity have already been observed, see: A. Mamontov, A Martin-Mingot, B. Métayer, O. Karam, F. Zunino, F. Bouazza, S. Thibaudeau Chem. A. Eur. J. 2020 DOI : 10.1002/chem.202000902.

[32] CCDC 2014659 (4b) contains the supplementary crystallographic data for this paper. These data can be obtained free of charge from The Cambridge Crystallographic Data Centre.

[33] G. A. Olah, D. Klumpp, Superelectrophiles and their chemistry; John Wiley and Sons; New York, 2008.

[34] T. Cernak, K. D. Dykstra, S. Tyagarajan, P. Vachal, S. W. Krska, Chem. Soc Rev. 2016, 45, 546-576. 


\section{Entry for the Table of Contents}

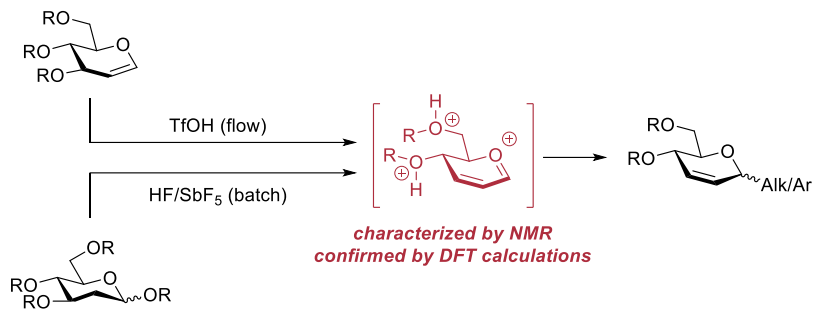

The cyclic allyloxycarbenium ion, the key intermediate in the Ferrier rearrangement, has been generated and accumulated under TfOH flow conditions. It has also been shown to be stable under superacid $\mathrm{HF} / \mathrm{SbF}_{5}$ solutions. Its long-lived character in these nonnucleophilic conditions allowed its full characterization by low-temperature NMR combined with DFT calculations. This ionic species proved to be synthetically useful and produced a range of original heteroatom-containing $C$-aryl pseudoglycals under these superacid conditions. 